\title{
The effects of genetic profiling on eating behaviour
}

\author{
C.A-M Graham, L. Pilic and Y. Mavrommatis \\ School of sport, health and applied science, St Mary's University Twickenham TWI 4SX, UK
}

This abstract was presented as the Cellular and Molecular Nutrition Theme Highlight

Obesity is preventable ${ }^{(1)}$. Today, more than 1.9 billion adults are overweight and 600 million are obese worldwide ${ }^{(1)}$. The influence genetic predisposition has on body weight is a rapidly increasing area in research ${ }^{(2)}$. One of the most evident single nucleotide polymorphisms (SNP) associated with obesity is the rs9939609 located in the first intron of the fat mass and obesity associated (FTO) gene $^{(2)}$. Individuals with the A-allele are associated with a $20-30 \%$ increased risk of obesity ${ }^{(2)}$. It has been suggested that risk is associated with both psychological and physiological mechanisms in food choice regulation ${ }^{(3)}$. Genetic information is now widely available to the public. However, there is little research exploring whether knowledge of obesity-related risk elicits a response in the average individual to change their behaviour. The aim of this study was to explore habitual eating behaviour and demonstrate whether the knowledge of genetic risk of the rs9939609 SNP changes dietary intake.

A cross-sectional study was carried out on 45 participants ( 33 females, 12 males) aged 18 years and above, with a body mass index ranging from $18.4-30.4 \mathrm{~kg} / \mathrm{m}^{2}$. Participants were genotyped and categorised into either low or high risk groups, assessed for their behavioural appetite motivations and inhibitions (behavioural approach system and behavioural inhibition system (BISBAS) questionnaire) and assessed for their dietary intake (5-step multiple pass 24-hour dietary recall) pre and post knowledge of their genetic risk group (high risk $=\mathrm{AA} / \mathrm{AT}$, low risk $=\mathrm{TT}$ ).

Free sugar intake in females was reduced post knowledge of the high risk genotype $(45.2 \mathrm{~g} \pm 9.0 \mathrm{~g}$ to $29.7 \mathrm{~g} \pm 6.8 \mathrm{~g}, \mathrm{p}<0.05)$, displayed in figure 1A. Snack intake in females was also reduced post knowledge in the high risk group $(213.6 \mathrm{~g} \pm 48.0 \mathrm{~g}$ to $80 \cdot 2 \mathrm{~g} \pm$ $19 \cdot 1 \mathrm{~g}, \mathrm{p}<0.05)$ displayed in figure 1B.
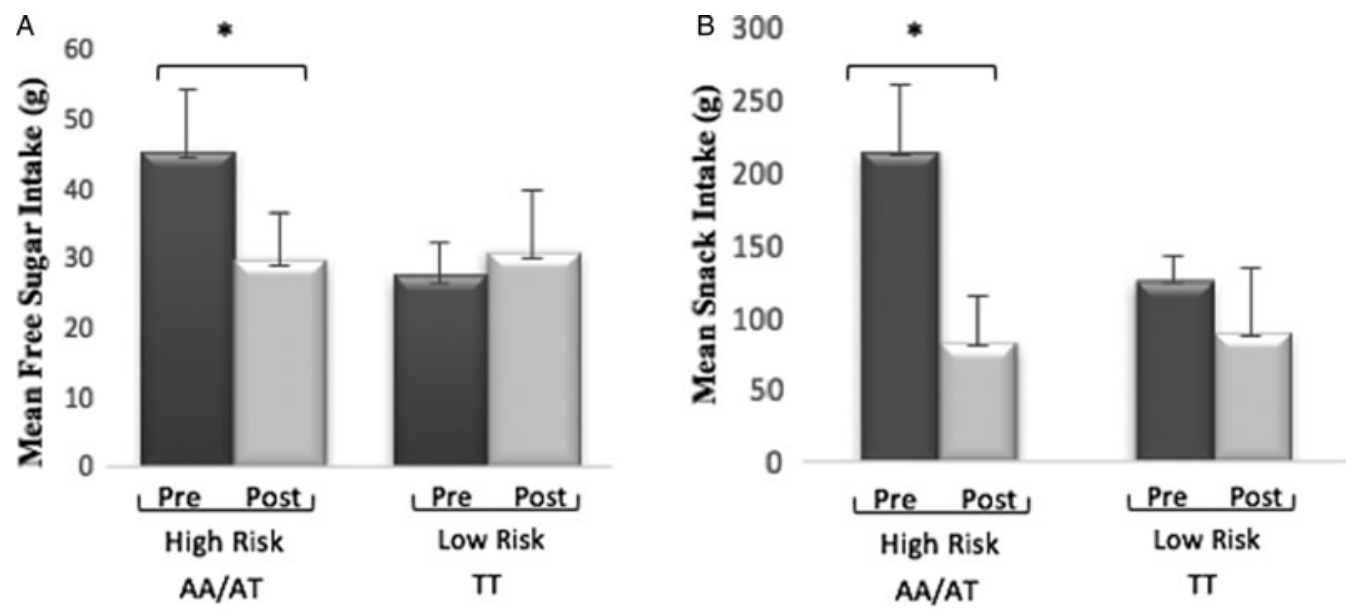

${ }^{\star} \mathrm{p}<0.05$, pre = pre knowledge of genotype, post = post knowledge of genotype.

Fig. 1. Mean (+SE) of free sugar intake (A) and snack intake (B) of females pre and post knowledge of genetic risk group, in the high and low risk groups.

These results confirm that the knowledge of an individual's genetic predisposition can have an effect on short-term food choice in those with high risk genotypes. The dietary choices that were significantly altered post knowledge of genetics are components of food types that are perceived as unhealthy demonstrating a shift towards healthy eating ${ }^{(4)}$. Further research is needed to determine longterm behavioural effects, of which the implications could contribute towards obesity prevention schemes.

1. World Health Organisation. (2016) Obesity and overweight. http://www.who.int/mediacentre/factsheets/fs311/en/

2. Frayling TM, Timpson NJ, Weedon MN et al. (2007) Science 16, 889-94.

3. Wardle J, Carnell S, Haworth CMA et al. (2008) J Clin Endocrinol Metab 93, 3640-3.

4. National Obesity Observatory. (2011) Knowledge and attitudes towards healthy eating and physical activity: what the data tells us. http://www.noo. org.uk/uploads/doc/vid_11171_Attitudes.pdf. 